\title{
Pulmonary ARTERIOVENOUS MALFORMATIONS IN CHILDREN AND YOUNG ADULTS
}

\author{
Bolesław Papla ${ }^{1}$, Magdalena Bialas ${ }^{1}$, Katarzyna UrbańczyK ${ }^{1}$, Barbara Skuza ${ }^{2}$, \\ JOACHIM BUCHWALD ${ }^{2}$
}

${ }^{1}$ Chair and Department of Pathomorphology, Jagiellonian University Medical College, Cracow, Poland
2Institute of Tuberculosis and Lung Disease, Branch in Rabka, Poland

\begin{abstract}
Authors observed five cases of lung arteriovenous malformations in children and young adults. Clinical data and morphological pictures of these lesions were presented.
\end{abstract}

Key words: pulmonary arteriovenous malformation, pulmonary angioma, arteriovenous angiomatosis, pulmonary arteriovenous aneurysm.

\section{Introduction}

Pulmonary vascular lesions are known under a variety of names including pulmonary arteriovenous malformation (PAVM), pulmonary arteriovenous aneurysm (PAVA), pulmonary angioma, arteriovenous angiomatosis, cavernous or venous haemangioma, pulmonary arteriovenous fistula and pulmonary hamartoma [1-4]. The majority of authors believe that the so-called venous haemangioma, especially congenital and occurring in children, should be classified as a vascular malformation since it does not fulfil all the criteria of a true neoplasm. Since the abnormalities referred to above are not neoplastic in nature, the commonly used names: cavernous or venous haemangioma seem less justified, although being conventionally used. The spectrum of pulmonary lesions ranges from multiple microscopic telangiectasias to individual large aneurysmal structures [5].

Pulmonary arteriovenous malformations (pulmonary haemangiomas) are a rare disease $[6,7]$. In most cases, they are congenital lesions occurring predominantly in children (over $80 \%$ of cases). Only in isolated cases - in the elderly - they are acquired and may be associated with chest injury, liver cirrhosis, mitral stenosis, infections (actinomycosis, schistosomiasis) and amyloidosis $[1,6,8]$. According to the literature, $47-80 \%$ of all cases of congenital arteriovenous malformations are accompanied by other syndromes, especially Osler-Weber-Rendu disease which is also known un- der the name of hereditary haemorrhagic telangiectasia (HHT) $[1,8]$. In 5-15\% of cases HHT coexists with pulmonary vascular malformations with a genetic component. Families, in which such malformations are identified, have a markedly higher rate of genetic disorders. Chromosomal abnormalities in HHT patients are identified in $9 \mathrm{q} 33-\mathrm{q} 34$ or $12 \mathrm{q}$, which triggers disorders in the formation of endoglin, a TGF- $\beta$ (transforming growth factor $\beta$ ) binding protein of endothelial cells $[1,9,10]$.

Lung arteriovenous malformations in children may result in various functional disorders of the lungs and heart, but typically they are symptomless [1] and are detected incidentally during examinations carried out due to other ailments [11-14]. In our pulmonary material we had five cases of these malformations, three of which occurred in infants and two in teenagers. Three cases were in female patients and two - in males.

\section{Case reports}

\section{Case 1}

A 1.5-year-old girl (RP) with no previous medical problems was admitted to hospital after drinking a small amount of liquid hair straightener. While in hospital, chest radiography and CT were performed. Large emphysematous bullae were revealed in segment 7 of the right lung, and in segments 9 and 10 of the left lung, together with focal densities and areas of atelectasis in 
their vicinity (Fig. 1). In December 2010, the middle lobe of the right lung was resected. Macroscopic examination showed a large emphysematous cyst and smaller blood-filled areas. Histological examination revealed in the lung multiple cavitary and cystic areas with endothelial lining, filled with blood (Fig. 2). Immunohistochemical tests demonstrated the endothelium to be positive for CD31 and negative for D2-40. Endothelium-lined papillary structures were also identified in one of the large cavities (Fig. 3). The walls of large vascular cysts had areas with a variable number of smooth muscle bands which were positive in immunohistochemical reaction with actin and desmin antibodies (Fig. 4). Large unlined interstitial emphysematous bullae were also found in the lungs. They may have arisen as a result of dilated large blood vessels compressing the bronchi. After several months the child,

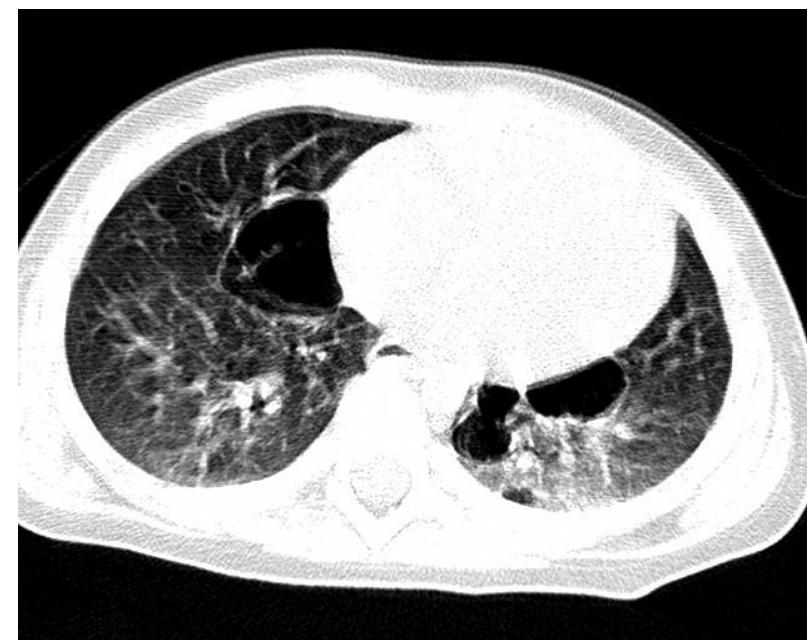

Fig. 1. CT of the chest (case 1): Large emphysematous bullae (dark) and focal arteriovenous densities and areas of atelectasis in their vicinity (bright) were present in both lungs

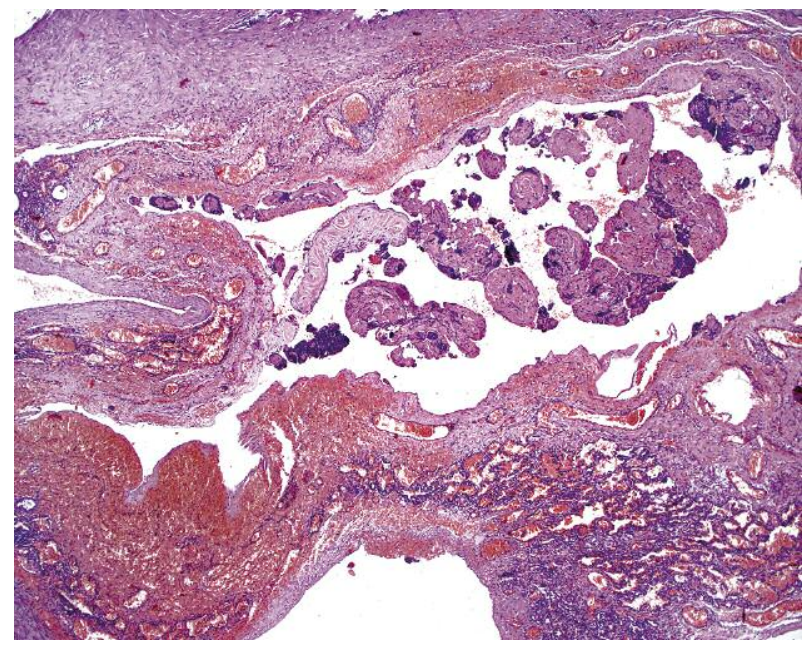

Fig. 3. Papillary structures in one of the cavities in a good general condition, was prepared for a surgical procedure in the other lung. In February 2011, the inferior lobe of the left lung, affected by similar lesions to the right lung, was resected.

\section{Case 2}

The case concerned an 18-year-old male patient (SP) with no clinical symptoms. Radiographic tests performed due to other medical issues showed lesions suggestive of arteriovenous malformations in the inferior lobe of the left lung. The entire inferior lobe of the left lung was surgically resected (Fig. 5). The tissue was fixed in formalin. The resulting histological preparations revealed numerous large (up to several centimetres in diameter) vascular spaces located subpleurally. The spaces were lined with typical endothelium and contained blood (Fig. 6). Smaller spaces resembled cavernous hae-

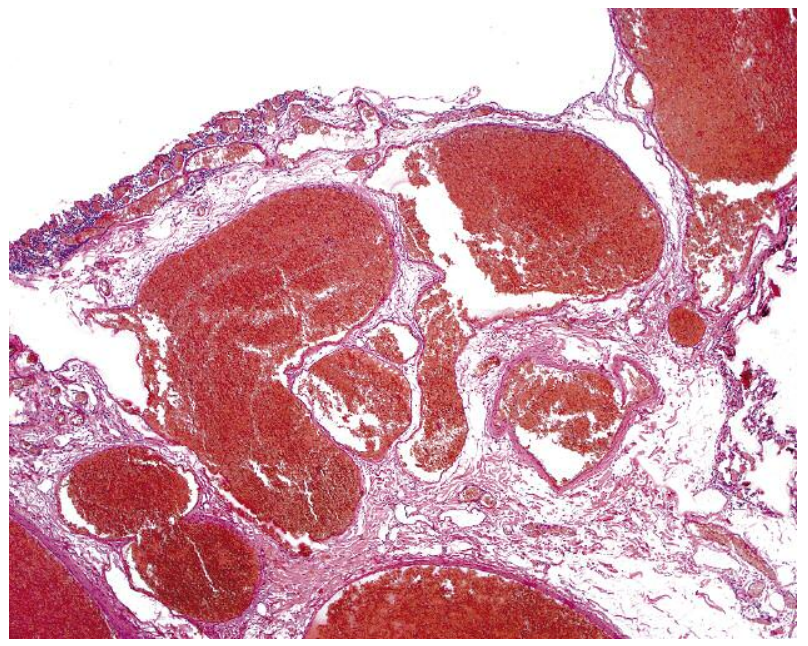

Fig. 2. Multiple cavities and cystic areas of PAVM filled with blood

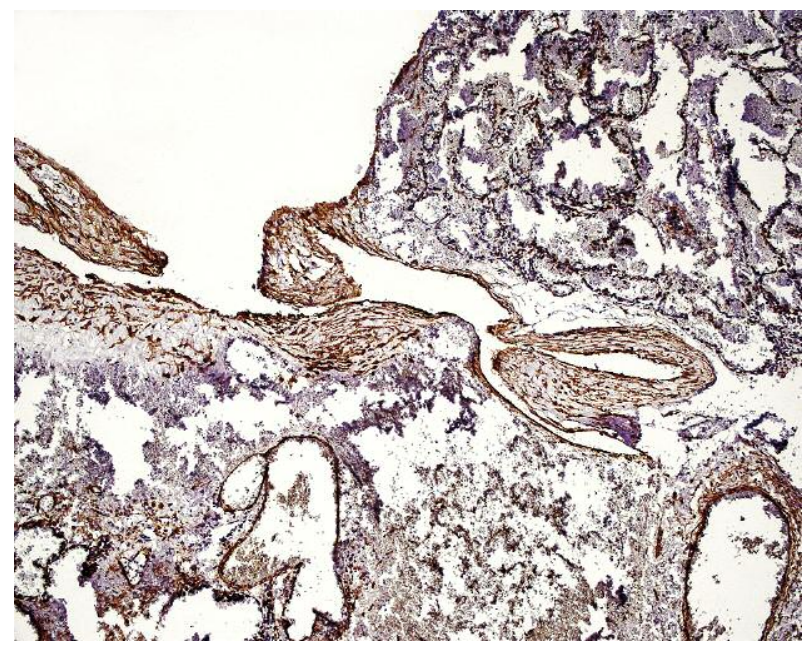

Fig. 4. Immunohistochemical reaction with SMA antibody - positive smooth muscle bands in part of the vascular structure wall 


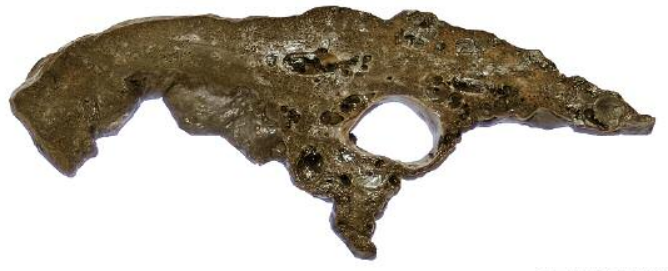

1756783

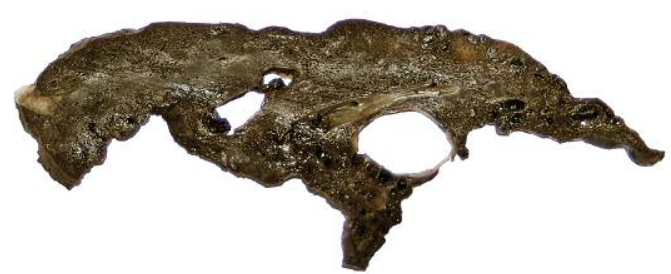

Fig. 5. Macroscopic picture of the removed lobe of the left lung (case 2)

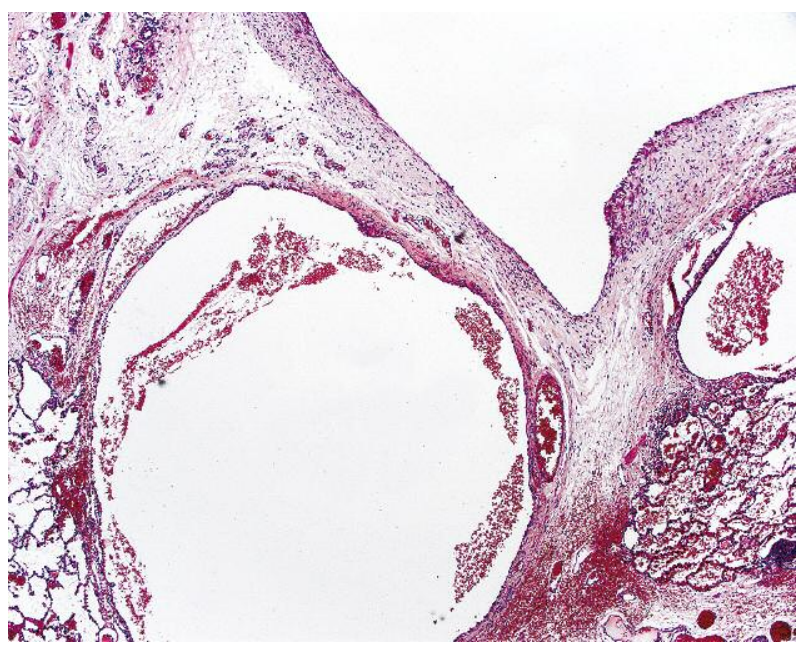

Fig. 7. Large vascular spaces lined with endothelium and partially filled with blood

mangiomas with sparse or more conspicuous amounts of connective tissue between lacunar areas. The walls of large vascular spaces were shown to have foci of smooth muscle bands of variable thickness. The bands were positive for actin and desmin. Focally the cyst wall consisted only of endothelium and a small amount of connective tissue. The surrounding pulmonary parenchyma showed foci of atelectasis and signs of fresh blood extravasation. Following surgery the patient was discharged in a good general condition.

\section{Case 3}

A girl (KS) delivered at term by Caesarean section, suffering from respiratory disorders since birth. CT performed on the first day of life showed a solid mass located in the upper left lung field, structurally indicative of airless lung. Left-sided thoracotomy revealed a homogeneous mass in the left pleural cavity, penetrated by two arteries from the aortic arch, attached via a short stalk to the pulmonary hilus and compressing the remaining pul-

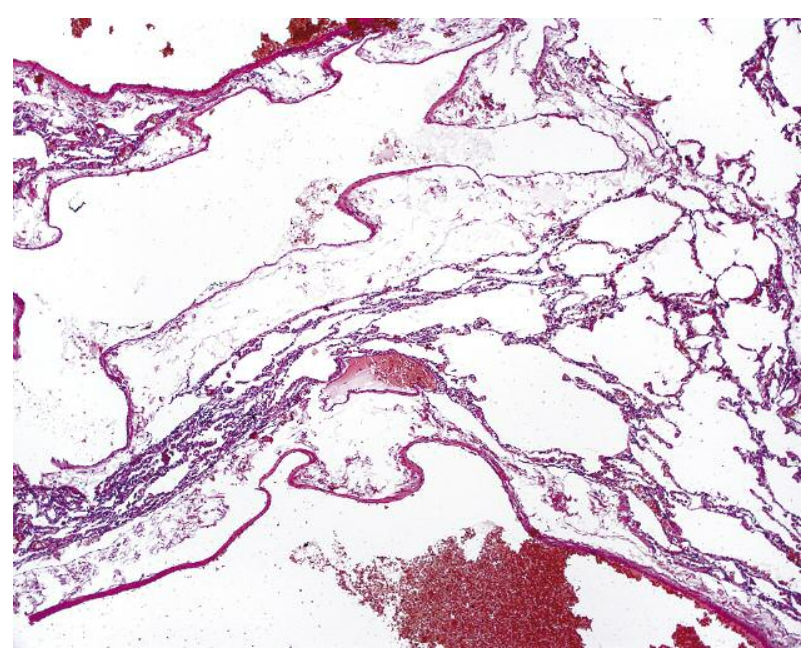

Fig. 6. Large vascular spaces lined with endothelium and partially filled with blood

monary parenchyma. During the first surgery, the accessory lobe of the left lung was removed. During the second procedure, performed at the Pediatrics Institute in Cracow, a larger portion of the left lung was removed. Lung specimens revealed typical features of a vascular malformation with aggregates of large vascular spaces, with partially present muscle walls, and smaller cavitary spaces resembling haemangioma. The surrounding pulmonary parenchyma showed signs of atelectasis and blood extravasation. The material collected during the second surgery also provided evidence of a small haemorrhagic infarct of the lung. Arterial vessels contained partially recanalized thrombi. Following the second surgery, the child's condition improved gradually.

\section{Case 4}

A boy (TJ) aged 14 who had been suffering from recurrent bronchitis and lower limb pain ever since kindergarten age. When the patient was 10, pain in the upper limbs and problems with gait emerged. The boy was repeatedly hospitalized due to the diagnosis of juvenile idiopathic arthritis. Lung CT revealed the presence of micronodular lesions and minor bronchiectasis within the superior and middle lobes of the right lung. During thoracotomy, multiple whitish spots were found on the pulmonary pleura and three specimens were harvested from the third segment of the right lung. Histologically, pulmonary parenchyma included large vascular spaces with partial muscle walls, surrounded by multiple thin-walled cavitary structures lined only with endothelial cells and filled with blood (Fig. 7). Loose connective tissue was also identified in their immediate vicinity. Furthermore, pulmonary parenchyma contained lymphocyte aggregates in the form of lymphoid follicles, occasionally with reactive centres, and fibrosis of the stroma of varying intensity - possibly suggestive of lymphocytic interstitial pneumonia (LIP). 


\section{Case 5}

A 2-month-old girl (SE) born pre-term, with right pulmonary hypoplasia and oesophago-bronchial fistula. The girl underwent surgery at the Provincial Hospital in Zielona Góra, where the oesophago-bronchial fistula was closed. After the surgery, the right lung was normally aerated for some time, however signs of partial atelectasis developed later. The infant was reoperated to remove a part of the atelectatic parenchyma of the right lung. Histological preparations made from the material resected during the surgery revealed the presence of a vascular malformation in the lung, indicative of cavernous and venous angioma. In histological terms, there were large blood vessels with partially muscular walls, forming irregular patterns and extending as far as the pleura. Also the pleura showed multiple cavitary and smaller vascular spaces resembling cavernous haemangioma. Additionally, signs of focal atelectasis were detected in the pulmonary parenchyma.

\section{Discussion}

Pulmonary vascular malformations occur more frequently in women than in men, which is also evidenced in our case reports. As for clinical manifestations, if any occur, they comprise chiefly dyspnoea due to the right to left shunt, haemoptysis and CNS symptoms secondary to embolisms [15-17]. It is to be presumed that the embolisms caused some of the clinical symptoms noted in the patient from Case 4.

Medical literature demonstrates that the majority of PAVM-type lesions develop in inferior lung lobes. In ca. 30\% of cases they are multiple and in ca. 15\% they occur bilaterally $[6,18,19]$. Frequently they involve subpleural abnormalities which can lead to haemorrhage into the pleural cavity [20]. Anabtawi et al. distinguish five different types of these malformations - based on anatomical and embryological assessment:

- group 1: multiple small arteriovenous fistulas, without aneurysm,

- group 2: large arteriovenous aneurysm,

- group 3:

-3A: large arteriovenous aneurysm (central),

$-3 \mathrm{~B}$ : large arteriovenous aneurysm with anomalous venous drainage,

-3C: multiple small arteriovenous fistulas with anomalous venous drainage,

- group 4:

$-4 \mathrm{~A}$ : large venous aneurysm with systemic artery communication,

- 4B: large venous aneurysm without fistula,

- group 5: anomalous venous drainage with fistula.

They claim that the formation of pulmonary arteries, capillaries and veins during foetal development progresses separately, which may trigger both simple and complex vascular defects within the lungs. According to Cooley et al. [21], the most common vascular anomaly is a primitive venous plexus with large vascular channels of the aneurysmal type.

The clinical diagnosis of the malformations is relatively uncomplicated: in addition to physical examination, cases with clinical manifestations can be diagnosed with an aid of chest X-ray, CT or MR as well as ultrasound scanning with colour Doppler imaging. Abnormalities are visible as oval or round-shaped shadows of homogeneous consistency, between 1 and $5 \mathrm{~cm}$ in diameter. Clinical diagnosis can be made in approximately $98 \%$ of cases $[1,22]$. Angiography and contrast echocardiography can also be used to unambiguously confirm the diagnosis.

The treatment of PAVM lesions (angiomas) often involves surgical resection, especially if an single lesion is found and in symptomatic patients. Also, tumour embolization is employed, either using embolic agents, stainless steel embolization coils, mini-balloons, cryotherapy, radiotherapy or laser therapy. Interferon $\alpha-2 \mathrm{a}$ and corticoid therapy have also been tried. The latter methods are not always fully effective, however they can be used, particularly in non-operative cases $[12,16,23-25]$.

Even though arteriovenous malformations are rare anomalies, they should be considered in the differential diagnosis of respiratory disorders in children and, in asymptomatic cases, in determining the nature of nodular pulmonary abnormalities in children.

\section{References}

1. Khurshid I, Downie GH. Pulmonary arteriovenous malformation. Postgrad Med J 2002; 78: 191-197.

2. Stringer CJ, Staney AL, Bates RC, et al. Pulmonary arteriovenous fistulas. Am J Surg 1955; 89: 1954-1980.

3. Le Roux BT. Pulmonary hamartomas. Thorax 1964; 19: 236-243.

4. Miettinen M. Hemangiomas, lymphangiomas and reactive vascular proliferations. In: Modern soft tissue pathology tumors and non-neoplastic conditions. Miettinen M (ed.). Cambridge University Press, Cambridge 2010; 574-604.

5. Burke CM, Safai C, Nelson DP, Raffin TA. Pulmonary arteriovenous malformations. A critical update. Am Rev Resp Dis 1986; 134: 334-339.

6. Yousem SA. Pulmonary vascular neoplasia. In: Progress in surgical pathology. Fenoglio-Preiser CM, Wolff M, Rilke F (eds.). Springer, Berlin 1989; 27-62.

7. Moran CA, Suster S. Tumors and tumor-like conditions of the lung and pleura. Vascular tumors of the lung. Saunders 2010: 248-249.

8. Gossage JR, Kanj G. Pulmonary arteriovenous malformations. A state of the art review. Am J Respir Crit Care Med 1998; 158: 643-661.

9. Guttmacher AE, Marchuk DA, White RI Jr. Hereditary hemorrhagic telangiectasia. N Engl J Med 1995; 333: 918-929.

10. Marchuk DA. The molecular genetic of hereditary hemorrhagic teleangiectasia. Chest 1997; 111 (6 Suppl): 79S-82S.

11. Kobayashi A, Ohno S, Bando M, et al. Cavernous hemangioma of lungs and liver in an asymptomatic girl. Respiration 2003; 70: 647-650. 
12. Capizzani TR, Patel H, Hines $\mathrm{MH}$, et al. A unique case of giant congenital pulmonary hemangioma in a newborn. J Pediatr Surg 2008; 43: 574-578.

13. Galliani CA, Beatty JF, Grosfeld JL. Cavernous hemangioma of the lung in an infant. Pediatr Prathol 1992; 12: 105-111.

14. Papla B, Białas M, Bulanda A, Skuza B. Pulmnary cavernous hemangioma. Pol J Pathol 2011; 61: (supl.) 3.

15. Chung Y, Ahrens WR, Singh J. Massive hemoptysis in a child due to pulmonary arteriovenous malformation. J Emerg Med 1997; 15: 317-319.

16. Zambudio AR, Calvo MJR, Lanzas JT, et al. Massive hemoptysis caused by tracheal hemangioma treated with interventional radiology. Ann Thorac Surg 2003; 75: 1302-1304.

17. Scully RE, Mark EJ, McNelly WF, et al. Case records of the Massachusetts General Hospital. Pulmonary arteriovenous malformations. Thalamic abscess. N Engl J Med 1990; 322: 1139-1148.

18. Corrin B, Nicholson AG. Pathology of the lungs: Vascular tumours and proliferations. Churchill, Livingstone, Elsevier, 2006: 74-76 and 620-621.

19. Fraire AE, Dail DH. Mesenhymal tumors Part II, Hemangioma. In: Dail and Hammar's pulmonary pathology. Vol. II. Neoplastic lung diseases. 3rd ed. Tomashefski JF Jr, Cagle FT, Farver CF Fraire AE (eds.). Springer 2008; 473-477.

20. Anabtawi IN, Ellison RG, Ellison LT. Pulmonary arteriovenous aneurysm and fistulas. Ann Thorac Surg 1965; 1: 277-285.

21. Cooley DA, McNamara DG. Pulmonary teleangiectasia: report of a case proved by pulmonary biopsy. J Thorac Surg 1954; 27 : 614-622.

22. Dines DE, Seward JB, Bernatz PE. Pulmonary arteriovenous fistulas. Mayo Clin Proc 1983; 58: 176-181.

23. Fine SW, Whitney KD. Multiple cavernous hemangiomas of the lung: a case report and review of the literature. Arch Pathol Lab Med 2004; 128: 1439-1441.

24. English JC. Pulmonary vascular lesions. In Cagle PT ed. Diagnostic pulmonary pathology. New York, Basel Marcel Dekker 2000; 368-369.

25. Lee DW, White RI Jr, Egglin TK, et al. Embolotherapy of large pulmonary arteriovenous malformations: long-term results. Ann Thorac Surg 1997; 64: 930-940.

\section{Address for correspondence}

\section{Bolesław Papla MD}

Chair and Department of Pathomorphology

Jagiellonian University Medical College

ul. Grzegórzecka 16

31-531 Kraków, Poland

e-mail:Bolekpapla@gmail.com 